\title{
Identificação de clusters industriais: um estudo quantitativo no estado de Santa Catarina
}

\author{
Identification of industrial clusters: a quantitative study in the state of Santa \\ Catarina
}

Identificación de clústeres industriales: un estudio cuantitativo en el estado de
Santa Catarina

\author{
Sérgio Begnini ${ }^{1}$ \\ Carlos Eduardo Carvalho ${ }^{2}$
}

Recebido em 03/11/2020; revisado e aprovado em 23/11/2020; aceito em 28/12/2020 DOI: http://dx.doi.org/10.20435/inter.v22i2.3206

\begin{abstract}
Resumo: Entender o funcionamento da dinâmica produtiva de uma região possibilita aumentar a eficiência e a competitividade, visto que empresas que atuam em clusters apresentam relevante papel no desenvolvimento econômico local e regional. Assim, torna-se importante identificar os clusters presentes em uma economia, visto a possibilidade de entender o perfil produtivo de determinada região. O objetivo principal deste trabalho é identificar a existência de clusters industriais na economia catarinense, evidenciando aspectos relacionados à dinâmica produtiva do estado. Com a utilização de dados, relativos ao ano de 2017, extraídos da Relação Anual de Atividades Econômicas (RAIS), de acordo com a Classificação Nacional de Atividades Econômicas (CNAE), procedeu-se de acordo com a metodologia de Britto e Albuquerque (2002), considerando os critérios de especialização, participação e densidade. Foram encontrados clusters em algumas regiões do estado catarinense, contudo a região considerada mais industrializada concentrou maior número de clusters. Os resultados indicam também que os clusters são formados, majoritariamente, por micro e pequenas empresas. Quanto a sua tipologia, os clusters identificados apresentam aspectos que os caracterizam como "informais", podendo também ser "organizados".
\end{abstract}

Palavras-chave: cluster industrial; Santa Catarina; quociente locacional; participação relativa; emprego.

Abstract: Understanding the functioning of the productive dynamics of a region makes it possible to increase efficiency and competitiveness, as companies operating in clusters play a relevant role in local and regional economic development. Thus, it is important to identify the clusters present in an economy, given the possibility of understanding the productive profile of a given region. The main objective of this work is to identify the existence of industrial clusters in Santa Catarina economy, highlighting aspects related to the productive dynamics of the state. Using data for 2017, extracted from the Annual List of Economic Activities (RAIS), according to the National Classification of Economic Activities (CNAE), proceeded according to the methodology of Britto and Albuquerque (2002), considering the criteria of specialization, participation, and density. Clusters were found in some regions of the Santa Catarina State; however, the region considered more industrialized concentrated more clusters. The results also indicate that the clusters are formed mainly by micro and small companies. As for their typology, the identified clusters present aspects that characterize them as "informal" and can also be "organized".

Keywords: industrial cluster; Santa Catarina; location quotient; relative participation; employment.

Resumen: Comprender el funcionamiento de la dinámica productiva de una región permite aumentar la eficiencia y la competitividad, ya que las empresas que operan en clústeres desempeñan un papel relevante en el desarrollo económico local y regional. Por lo tanto, es importante identificar los clústeres presentes en una economía, dada la posibilidad de comprender el perfil productivo de una región determinada. El objetivo principal de este trabajo es identificar la existencia de clústeres industriales en la economía de Santa Catarina, destacando aspectos relacionados con la dinámica productiva del estado. Utilizando datos para 2017, extraídos de la Lista Anual de Actividades Económicas (RAIS), de acuerdo con la Clasificación Nacional de Actividades Económicas (CNAE), se procedió de acuerdo con la metodología de Britto y Albuquerque (2002), considerando los criterios de especialización, participación y densidad. Se encontraron grupos en algunas regiones del estado de Santa Catarina, sin embargo, la región considerada más industrializada fue la

\footnotetext{
${ }^{1}$ Universidade Federal da Fronteira Sul (UFFS), Universidade do Oeste de Santa Catarina (UNOESC), Chapecó, Santa Catarina, Brasil.

${ }^{2}$ Universidade do Oeste de Santa Catarina (UNOESC), Chapecó, Santa Catarina, Brasil.
} 
que concentró más grupos. Los resultados también indican que los clústeres están formados principalmente por micro y pequeñas empresas. En cuanto a su tipología, los clústeres identificados tienen aspectos que los caracterizan como "informales", y también pueden ser "organizados".

Palabras clave: clúster industrial; Santa Catarina; cociente de ubicación; participación relativa; empleo.

\section{INTRODUÇÃO}

A identificação de clusters é abordada pela literatura, apontando para a importância de estudar as aglomerações de empresas, principalmente como geradores de competitividade. Ao atuar de forma aglomerada, as empresas, principalmente as de pequeno e médio porte, têm a possibilidade de vencer barreiras, crescer e obter vantagens competitivas, além de oportunizarem emprego e certas inovações (ANTUNES-FERREIRA; SANTOS-NATÁRIO; MARTINS-BRAGA, 2018). Empresas que atuam em aglomerações apresentam importante papel para o desenvolvimento econômico regional, desencadeando efeitos positivos sobre o emprego, a inovação e a transferência de conhecimento (BERKECZ-KOVÁCS, 2018). Segundo Iglioni (2001), entender o funcionamento produtivo de uma região permite compreender o aumento da eficiência e da competição das empresas nos países, sejam eles desenvolvidos ou em desenvolvimento. A identificação de cluster possibilita visualizar o perfil produtivo de determinadas regiões.

Referente ao estado de Santa Catarina, alguns estudos apontaram e/ou discutiram a existência de clusters. Campos, Nicolau e Cário (2000), bem como Scur e Garcia (2019), abordaram questões relativas ao cluster da indústria cerâmica de revestimento no sul do estado. Lins (2000), por uma análise descritiva, discutiu possibilidade da existência de um cluster turístico em Florianópolis.

Osinski et al. (2014) partiram do princípio da existência de nove clusters: (i) agroindustrial; (ii) eletrometal-mecânico; (III) madeireiro; (iv) logístico; (v) Confecção; (vi) cerâmico; (vii) tecnológico; (viii) moveleiro; (ix) têxtil. Tais clusters teriam sido identificados pelo governo do estado de Santa Catarina. Vianna e Hoffmann (2009) debateram sobre a existência de clusters turísticos culturais, utilizando o escalonamento multidimensional e a análise de correspondências múltiplas. MeyerStamer (1998), por meio de descrições, aponta cinco clusters estabelecidos: (i) têxtil; (ii) metais e eletroeletrônica; (iii) processamento de alimentos; (iv) cerâmica; (v) móveis. Andrade (2002) estudou o cluster têxtil do vale do Itajaí.

Nota-se que os estudos apontam a existência de clusters. Contudo não foram encontrados estudos científicos que abordassem a identificação de clusters industriais em Santa Catarina, considerando todos os municípios e setores industriais. Assim, propõe-se a avançar a discussão quanto à identificação de clusters industriais em Santa Catarina, a partir de uma metodologia quantitativa válida, utilizando dados oficiais. A questão de pesquisa estruturada foi a seguinte: quais clusters industriais podem ser identificados no estado de Santa Catarina? O objetivo principal é identificar a existência de clusters industriais na economia catarinense, evidenciando aspectos da dinâmica produtiva do estado.

Este estudo utiliza a Classificação Nacional de Atividades Econômicas (CNAE) para classificar os dados extraídos da Relação Anual de Informações Sociais (RAIS). Os dados extraídos da RAIS são relativos ao ano de 2017. Para a identificação dos clusters, foi utilizada metodologia desenvolvida por Britto e Albuquerque (2002), consistindo nos critérios de (i) especialização; (ii) participação; (iii) densidade. 
Este estudo contribui academicamente, ao identificar, com base em uma metodologia já testada, os clusters industriais catarinenses, de forma que foram considerados todos os municípios e setores industriais, acrescentando à literatura que até o momento apresenta estudos sobre a identificação de clusters, mais pela observação de alguns fatores. Gerencialmente, contribui ao possibilitar a compreensão mais profunda da estrutura industrial produtiva do estado e elementos que a compõem, auxiliando os gestores a tomar decisões estratégicas de investimentos ou custos. Contribui também ao identificar que os clusters industriais catarinenses são majoritariamente formados por empresas de pequeno porte, o que, segundo Crocco et al. (2003), seria um facilitador para que essas empresas possam crescer.

\section{REFERENCIAL TEÓRICO}

A aglomeração de empresas tornou-se relevante nos estudos sobre estratégia competitiva. Entendendo o cluster como uma concentração geográfica e setorial de empresas (SCHMITZ, 1999), buscou-se identificar formações de aglomerados do tipo clusters no estado de Santa Catarina.

\subsection{Atuação em clusters}

Pesquisadores e formuladores de políticas demonstraram interesse crescente em estudar clusters, principalmente no decorrer dos anos 1990 (ALDERETE; BACIC, 2020). Das diversas pesquisas que foram realizadas abordando clusters, algumas indicam a possibilidade e a importância de existir compartilhamento de conhecimento, bem como do incentivo à colaboração e à aprendizagem (BRESCHI, 2001; GLAESER et al., 1992; JAFFE; TRAJTENBERG; HENDERSON, 1993). Alguns estudos enfatizam a importância do cluster como gerador de competitividade entre as empresas (ANTUNES-FERREIRA; SANTOS-NATÁRIO; MARTINS-BRAGA, 2018; CONNELL; VOOLA, 2013; YUSUF et al., 2014). Outras pesquisas indicam que empresas geograficamente próximas têm a possibilidade de compartilhar recursos e conhecimento, ao mesmo tempo que competem, possibilitando retornos crescentes de escala (HILL; BRENNAN, 2000).

A proximidade geográfica entre as empresas, como facilitadora do crescimento econômico, foi introduzida por Alfred Marshall (2013). Vários outros estudos foram realizados a partir de então. Porter (1998) identificou que as empresas aglomeradas, formando clusters, desenvolvem força competitiva, tanto no nível local quanto no nível global. Localmente, a rivalidade pode gerar a falência de algumas empresas e fusão de outras, e as que sobrevivem ficam mais fortes para competir local e globalmente, de forma que a concorrência local impele as empresas a buscarem a inovação e ampliarem as vantagens competitivas (BERKECZ-KOVÁCS, 2018; PORTER, 1990).

Visualizando que a participação em um cluster influencia o comportamento das empresas (PORTER, 1998), vários pesquisadores, passaram a dedicar maior atenção para o fato de que a aglomeração de empresas gera vantagem competitiva (TADDEO et al., 2017; WALUSZEWSKI, 2004). A década de 1990 ficou marcada pelas discussões sobre a concentração de empresas inter-relacionadas (WALUSZEWSKI, 2004), e a atuação em clusters recebeu maior atenção. Cluster pode ser entendido como um aglomerado de empresas, em determinado espaço (um município, uma nação, ou um estado), próximas geograficamente (PORTER, 2008) e que, de alguma forma, estão interligadas vertical ou horizontalmente (BRITTO; ALBUQUERQUE, 2002).

A definição de cluster pode variar de acordo com a região geográfica, dependendo dos segmentos em que competem e das estratégias das empresas (PORTER, 2008). Cada cluster 
apresenta uma realidade distinta, existindo aqueles que estão mais e aqueles que estão menos concentrados geograficamente (BERGMAN; FESER, 1999; LARENTIS; GIOVANELLA; CISLAGHI, 2013). Mais que um conjunto de produtores locais aglomerados (MOSSIG; SCHIEBER, 2016), o cluster é um sistema de relações e conexões que ocorrem ao longo do tempo de vida do aglomerado (SCUR; GARCIA, 2019). O cluster é formado por empresas que estruturam uma rede de relacionamentos em determinada região geográfica, possibilitando proximidade e interações entre elas, de modo que as similaridades e as complementariedades possibilitam manter relações voltadas tanto para a competição como para a cooperação (AZIZ; NORHASHIM, 2008; BERKECZKOVÁCS, 2018).

Além dos clusters, a literatura mostra outros tipos de aglomerados para descrever concentrações de empresas. Cada um possui características próprias e características comuns (BERGMAN; FESER, 1999). Em seu estudo, Giuliani (2005) classifica os aglomerados em localidades econômicas, sejam eles clusters, distrito industrial, localidade industrial, Milieu innovateur ou distrito tecnológico.

A maioria das empresas que participam de um cluster não compete diretamente entre si, visto que atuam em diferentes segmentos (PORTER, 1998). Os ganhos estão, principalmente, na redução de custos e de riscos para o negócio, na conquista de escala e espaço no mercado, no acesso a soluções que atendam às necessidades, na possibilidade de maior aprendizado, na geração de inovações, bem como na possibilidade de firmar e manter relações e parcerias (VERSCHOORE; BALESTRIN, 2008). As empresas podem também cooperar umas com as outras (ANTUNES-FERREIRA; SANTOS-NATÁRIO; MARTINS-BRAGA, 2018). Mesmo não sendo um requisito para que um cluster seja estabelecido, a atuação das próprias empresas leva ao estabelecimento de interações cooperativas (ANTUNES-FERREIRA; SANTOS-NATÁRIO; MARTINS-BRAGA, 2018).

Uma empresa, ao interagir com outras empresas em um cluster, passa a ter maiores chances de ser competitiva. Marshall entendeu, a partir de seus estudos, que a proximidade geográfica de pequenas empresas permitiria a redução de custos, bem como o alcance de oportunidades econômicas (AMIN, 2003). Uma vez que o ambiente de negócios está cada vez mais turbulento e dinâmico, participar de um cluster possibilita à empresa acesso a novas estratégias e a descoberta de novas oportunidades para competir (PORTER, 1998). A troca de conhecimentos e experiências, que é estabelecida dentro do cluster, possibilita às empresas aprender, inovar e competir (ANTUNES-FERREIRA; SANTOS-NATÁRIO; MARTINS-BRAGA, 2018). Em cada cluster, haverá um processo de aprendizagem, cooperação e competição (ANTUNES-FERREIRA; SANTOSNATÁRIO; MARTINS-BRAGA, 2018).

Gerolamo et al. (2008) identificam que muitos dos estudos sobre cluster mantêm atenção na importância das micro, pequenas e médias empresas (MPMEs) e o importante papel delas para a economia. Crocco et al. (2003) destacam que, por participarem de um cluster, empresas de diversos tamanhos, mas em especial as micro, pequenas e médias, têm vencido muitos desafios. Participar de um cluster possibilita o desenvolvimento da cooperação, de infraestrutura coletiva, de especialização de mão de obra, de especialização de produtos e serviços (CROCCO et al., 2006). Assim, participar de um cluster possibilita às empresas trocar experiências, buscar conhecimentos novos e desenvolver capacidades.

Formados, na maioria das vezes, por empresas de pequeno porte, os clusters possibilitam a geração de oportunidade de trabalho, de inovações e dinamismo na economia local e regional (ANTUNES-FERREIRA; SANTOS-NATÁRIO; MARTINS-BRAGA, 2018). Participar de um cluster 
possibilita que empresas de pequeno porte possam ser e permaneçam competitivas no mercado (NETO, 2000), visto que encontram mais vantagens em estarem dentro do cluster do que fora dele (CHAIN, 2018).

\subsection{Identificação de clusters}

A literatura apresenta uma série de estudos que buscaram identificar a formação de clusters ou outro aglomerado. Cada estudo utilizou uma ou mais medidas e informações: técnica de sintetização dos dados (escalonamento multidimensional) e de inferência estatística (análise de correspondência) (VIANNA; HOFFMANN, 2009); indicador de concentração (coeficiente de Gini locacional) e de especialização (Quociente Locacional [QL]) de atividades econômicas (SUZIGAN et al., 2004); análise de cluster e análise discriminante (HILL; BRENNAN, 2000); QL, tabela de Classificação Nacional de Atividades Econômicas (CNAE) para identificar a interdependência e/ou a similaridade das empresas, bem como a densidade e a complexidade das atividades (BRITTO; ALBUQUERQUE, 2002).

Antunes-Ferreira, Santos-Natário e Martins-Braga (2018) apresentam dois caminhos para a identificação de cluster: (i) com base em indícios estabelecidos a priori, validar se determinado aglomerado é realmente um cluster ou não; (ii) a partir de uma análise mais ampla, busca-se não apenas validar, mas identificar a existência de determinado cluster. Na segunda opção, após a identificação dos clusters, busca-se validar cada um, apontando as relações entre os agentes locais (BRAUNERHJELM; CARLSSON, 1999). Nota-se que é pertinente definir uma metodologia que identifique cada cluster e na qual seja possível apontar características desses (ANTUNESFERREIRA; SANTOS-NATÁRIO; MARTINS-BRAGA, 2018).

Entre outros estudos, Antunes-Ferreira, Santos-Natário e Martins-Braga (2018) utilizaram quatro indicadores para identificar a existência de clusters: (i) Quociente Locacional; (ii) Índice Hirschman-Herfindahl Modificado (IHHM); (iii) Índice de Participação Relativa; (iv) Coeficiente de Especialização. Piekarski e Torkomian (2005) descreveram quatro métodos quantitativos para identificação de clusters, que, segundo os autores, são utilizados, no Brasil, tanto por estudantes quanto por pesquisadores: (i) Quociente Locacional; (ii) Índice de Especialização; (iii) Metodologia Exploratória; (iv) Índice de Concentração (IC). Piekarski e Torkomian (2005) indicam, ainda, o método apresentado por Britto e Albuquerque (2002) substituindo o QL pelo IC, organizando as matrizes de superposição por IC, e não por QL.

Hill e Brennan (2000) desenvolveram um método para identificar os clusters de indústrias, nas quais uma região possui uma vantagem competitiva, utilizando análise de cluster e análise discriminante. Os autores definiram um cluster industrial competitivo como um aglomerado de empresas ou estabelecimentos que competem no mesmo setor, compartilham conhecimentos e mão de obra especializada, gerando diferencial competitivo. O cluster é constituído por relações de compra (fornecedor) e venda (consumidor) (encadeamentos para trás e para frente) entre as empresas motrizes e outras, que mantêm algum tipo de relacionamento, como compartilhamento de tecnologia e/ou trabalho (HILL; BRENNAN, 2000).

Considerando que em empresas de pequeno porte existe uma correlação positiva entre crescimento de emprego e concentração geográfica (cluster), Fingleton, Igliori e Moore (2005) buscaram identificar um cluster que, segundo eles, não é uma tarefa simples, utilizando a medida de QL. Os autores indicam que, por mostrar, em uma primeira versão, a identificação de um cluster, a medida QL é utilizada em vários estudos no campo. Mas é preciso ter cuidado ao mensurar o 
agrupamento (cluster), pois o QL mede a importância de uma indústria em determinada área comparando à realidade da região utilizada como referência (p. ex., estado ou país), contudo não abarca informações sobre o tamanho absoluto da indústria nesta mesma área (FINGLETON; IGLIORI; MOORE, 2005).

Para tratar esse problema, Fingleton, Igliori e Moore (2005) cruzaram valores de QL com uma medida de tamanho (número de empregos na indústria local), minimizando o excesso do número de emprego de um determinado setor na localidade selecionada, de forma a eliminar ou ao menos reduzir a possibilidade de uma determinada localidade apresentar um QL elevado, sendo o setor de pouca relevância em termos absolutos. Por fim, os autores adotaram a medida de agrupamento horizontal (HC), que mensura a intensidade do cluster considerando as pessoas ocupadas por km² (FINGLETON; IGLIORI; MOORE, 2005).

Bergman e Feser (1999) apontam que há uma série de ferramentas que podem ser utilizadas, algumas mais simples (QL) e outras mais complexas (insumo-produto). Os autores chamam atenção para o fato de que muitas das definições e dos métodos utilizados para definir um cluster possuem base em aspectos políticos, e não em modelos teóricos estabelecidos.

Segundo Britto e Albuquerque (2002), podem ser encontrados tanto estudos de cunho mais qualitativo quanto os que possuem abordagem mais quantitativa. Para os autores, os estudos qualitativos, geralmente estudos de caso, buscam definir critérios tendo como objetivo identificar as características próprias desses aglomerados e seus contornos formativos, enquanto os quantitativos estão associados a duas questões fundamentais, ligadas aos aglomerados: (i) similaridade (empresas que, mesmo tendo características diversas umas das outras, possuem competências complementares, possibilitando acesso a vários benefícios, inacessíveis para quem atua isoladamente); (ii) interdependência (a dinamicidade interna do cluster é gerada por meio dos relacionamentos estabelecidos entre as diferentes atividades/setores que o compõem). O cluster é, portanto, um agrupamento de empresas diferentes, mas que, de alguma forma, apresentam complementações umas para as outras (BRITTO; ALBUQUERQUE, 2002). É preciso considerar que cada cluster pode estar em diferente estágio de desenvolvimento, apresentando diferentes características quando comparado com outros (ANTUNES-FERREIRA; SANTOS-NATÁRIO; MARTINS-BRAGA, 2018; AZIZ; NORHASHIM, 2008).

\subsection{Tipologias dos clusters}

Não existe uma tipologia definida que possa abarcar todos os clusters, mesmo porque cada cluster apresenta-se em um território distinto, constituído por empresas que possuem histórias e recursos específicos. Segundo Andriani et al. (2005), um cluster tem cinco características: (1) conjunto de empresas e instituições especializadas em determinadas atividades econômicas, concentradas em uma região geográfica; (2) empresas que se relacionam e são complementares, formando uma rede com inputs e outputs; (3) as empresas integram uma rede de interdependência, que possibilita a cooperação, resultando em oportunidades de aprendizagem entre elas; (4) as tomadas de decisão são horizontais, sem uma linha hierárquica clara; (5) existência e participação de instituições privadas e públicas com potencial para suportar o crescimento do cluster.

Para Mytelka e Farinelli (2000), os clusters podem se formar espontaneamente em determinada região, podendo ser classificados em três tipos: (i) informais; (ii) organizados; (iii) inovadores. O Quadro 1 apresenta exemplos e características desses três tipos de clusters. 
Quadro 1 - Principais características de três tipos de clusters espontâneos

\begin{tabular}{|c|c|c|c|}
\hline \multirow{2}{*}{ Tipos de clusters } & \multicolumn{3}{|c|}{ Clusters espontâneos } \\
\cline { 2 - 4 } Exemplos & Clusters informais & Clusters organizados & Clusters inovadores \\
\hline Nível tecnológico & $\begin{array}{c}\text { Peças de automóveis } \\
\text { - Suame Magazine } \\
\text { (Kumasi, Gana) }\end{array}$ & $\begin{array}{c}\text { Peças de automóveis } \\
- \text { Nnewi (Nigéria). } \\
\text { Instrumentos cirúrgicos } \\
\text { Sialkot (Paquistão) }\end{array}$ & $\begin{array}{c}\text { Móveis - Jutlândia } \\
\text { (Dinamarca) } \\
\text { Armações de óculos - } \\
\text { Belluno (Itália) }\end{array}$ \\
\hline Habilidades & Baixo & Médio & Médio \\
\hline Inovação & Pouca & Médias & Altas \\
\hline Confiança & Pouca & Alguma & Alta \\
\hline Cooperação & Pouca & Alta & Alta \\
\hline Competição & Alta & Alta & Alta \\
\hline Tamanho das empresas & Micro e pequeno & Pequeno e médio & Pequeno, médio e grande \\
\hline Nível de exportações & Baixo ou nenhum & Médio-alto & Alto \\
\hline N. de atores críticos & Baixo & Baixo para médio & Alto \\
\hline Ligações & Algumas & Algumas & Extensas \\
\hline Mudança de produto & Pouca ou nenhuma & Alguma & Contínua \\
\hline
\end{tabular}

Fonte: Mytelka e Farinelli (2000) e United Nations Conference on Trade and Development (UNCTAD, 1998).

Os autores Rissete, Macedo e Meiners (2003), após analisar vários estudos, criaram uma tipologia de clusters, com cinco classificações: (i) informais; (ii) organizados; (iii) inovativos; (iv) incubadoras e parques tecnológicos; (v) radicais fordistas; (vi) radicais transnacionais. O Quadro 2 indica as características de cada um deles.

Quadro 2 - Características dos clusters segundo a tipologia

\begin{tabular}{|c|c|c|c|c|c|c|}
\hline Aspectos & $\begin{array}{c}\text { Clusters } \\
\text { informais }\end{array}$ & $\begin{array}{c}\text { Clusters } \\
\text { organizados }\end{array}$ & $\begin{array}{c}\text { Clusters } \\
\text { inovativos }\end{array}$ & \begin{tabular}{|l|} 
Incubadoras \\
parques \\
tecnológicos \\
\end{tabular} & $\begin{array}{l}\text { Clusters } \\
\text { radiais } \\
\text { fordistas }\end{array}$ & $\begin{array}{l}\text { Clusters radiais } \\
\text { transnacionais }\end{array}$ \\
\hline $\begin{array}{l}\text { Tamanho das } \\
\text { firmas }\end{array}$ & Micro & $\begin{array}{l}\text { Pequenas, } \\
\text { médias e } \\
\text { grandes }\end{array}$ & $\begin{array}{l}\text { Pequenas, } \\
\text { médias e } \\
\text { grandes }\end{array}$ & $\begin{array}{l}\text { Pequenas e } \\
\text { médias }\end{array}$ & $\begin{array}{l}\text { Médias e } \\
\text { grandes }\end{array}$ & $\begin{array}{l}\text { Médias e } \\
\text { grandes }\end{array}$ \\
\hline Confiança & Baixa & Alta & Alta & Alta & Baixa & Média \\
\hline Cooperação & Baixa & Alta & Alta & Baixa & Baixa & Média a alta \\
\hline $\begin{array}{l}\text { Existência de } \\
\text { liderança }\end{array}$ & Baixa & Baixa a média & Alta & Baixa a média & Média & Média a alta \\
\hline Especialização & Baixa & Média & Alta & Média & Média & Alta \\
\hline $\begin{array}{l}\text { Ligações em } \\
\text { rede }\end{array}$ & Algumas & $\begin{array}{l}\text { Algumas a } \\
\text { muitas }\end{array}$ & $\begin{array}{c}\text { Muitas } \\
\text { (extensivas) }\end{array}$ & Baixa & Hierárquica & Hierárquica \\
\hline $\begin{array}{c}\text { Nível } \\
\text { tecnológico }\end{array}$ & Baixo & Médio & Alto & Baixo a alto & Médio & Alto \\
\hline Inovações & Poucas & Algumas & Muitas & Algumas & Algumas & Muitas \\
\hline Aprendizado & Pequeno & Médio a alto & $\begin{array}{c}\text { Alto } \\
\text { (contínuo) } \\
\end{array}$ & Alto & Médio & Médio a alto \\
\hline $\begin{array}{l}\text { Mudança dos } \\
\text { produtos }\end{array}$ & $\begin{array}{c}\text { Baixa ou } \\
\text { nenhuma }\end{array}$ & Alguma & Contínua & Alta & Alguma & Alta \\
\hline Competição & Alta & Alta & Alta & Média & Média & Média \\
\hline
\end{tabular}




\begin{tabular}{|c|c|c|c|c|c|c|}
\hline Aspectos & $\begin{array}{c}\text { Clusters } \\
\text { informais }\end{array}$ & $\begin{array}{c}\text { Clusters } \\
\text { organizados }\end{array}$ & $\begin{array}{c}\text { Clusters } \\
\text { inovativos }\end{array}$ & $\begin{array}{c}\text { Incubadoras } \\
\text { parques } \\
\text { tecnológicos }\end{array}$ & $\begin{array}{c}\text { Clusters } \\
\text { radiais } \\
\text { fordistas }\end{array}$ & $\begin{array}{c}\text { Clusters radiais } \\
\text { transnacionais }\end{array}$ \\
\hline Mercado & Local & $\begin{array}{c}\text { Regional/ } \\
\text { nacional }\end{array}$ & $\begin{array}{c}\text { Nacional/ } \\
\text { internacional }\end{array}$ & $\begin{array}{c}\text { Nacional/ } \\
\text { internacional }\end{array}$ & Nacional & $\begin{array}{c}\text { Nacional/ } \\
\text { internacional }\end{array}$ \\
\hline Exportação & $\begin{array}{c}\text { Pouca ou } \\
\text { nenhuma }\end{array}$ & Alguma & Muita & Alguma & Alguma & Muita \\
\hline $\begin{array}{c}\text { Geração de } \\
\text { empregos } \\
\text { diretos }\end{array}$ & Elevado & Elevado & Baixo & Baixo & Médio & Médio \\
\hline $\begin{array}{c}\text { Multiplicador } \\
\text { regional }\end{array}$ & Baixo & Médio & Alto & Médio a alto & Alto & Médio \\
\hline
\end{tabular}

Fonte: Rissete, Macedo e Meiners (2003, p. 373).

Segundo a Organização para a Cooperação e Desenvolvimento Econômico (OCDE, 1999), os clusters podem ser classificados em quatro tipos: (i) microclusters; (ii) cluster industrial; (iii) cluster regional; (iv) megaclusters. Roelandt e Hertog (1999) indicam três níveis de classificação e análise de cluster: (i) macro; (ii) meso; (iii) micro. No nível macro (nível de país), o cluster congrega as ligações entre grupos de indústrias (megaclusters), e a análise ocorre na estrutura econômica, abrangendo os padrões de especialização de determinada economia. No nível meso (nível industrial/setorial), o cluster é visualizado nas relações inter e intraindústrias, e a análise é focada na busca por encontrar necessidades de inovação. No nível micro (nível de empresa), o cluster é entendido a partir das ligações interempresas, e a análise tem foco nas estratégias de negócios e no desenvolvimento de projetos voltados à inovação.

\section{PROCEDIMENTOS METODOLÓGICOS}

Este tópico aborda questões relativas aos procedimentos adotados para a identificação de clusters industriais no estado de Santa Catarina, a partir da metodologia elaborada por Britto e Albuquerque (2002). Porém os clusters identificados não serão analisados quanto a sua formação vertical ou horizontal. Para tal caracterização, são necessárias análises mais robustas (JOÃO; OLIVARES, 2014), não sendo este o objetivo deste estudo.

Os dados utilizados são referentes ao ano de 2017, extraídos da RAIS, de acordo com a CNAE 2.0, para cada um dos 295 municípios catarinenses. É preciso considerar que os dados da RAIS referem-se aos empregos formais, e, dentro do cluster, parte dos empregos pode ser informal (SUZIGAN et al., 2004). Contudo esses são os dados oficiais, sendo utilizados e aceitos também no meio acadêmico e científico, principalmente por apresentarem desagregação geográfica e setorial (SUZIGAN et al., 2004).

A metodologia de Britto e Albuquerque (2002) é adequada para a identificação de clusters (PIEKARSKI; TORKOMIAN, 2005) e considera três critérios: (i) especialização (QL>1); (ii) relevância (PR>1\% ou 2\%); (iii) densidade (mínimo de 10 empresas na divisão da CNAE e mínimo de 10 empresas em atividades associadas). Britto e Albuquerque (2002) compararam cada município brasileiro com o cenário nacional.

No presente estudo, por utilizar cada município em comparação ao estado de Santa Catarian (SC), e não ao país, considerou-se QL>3 para indicar especialização (REZENDE; CAMPOLINA; PAIXÃO, 2012). Para considerar que a economia do município é expressiva 
em relação à economia estadual, utilizou-se participação relativa $(P R)>10 \%$, a exemplo de Bittencourt e Campos (2009), que utilizaram PR>2,5\%. Para identificar a densidade, optou-se pelo indicado por Britto e Albuquerque (2002). A fórmula/explicação dos cálculos está apresentada no Quadro 3.

Quadro 3 - Fórmula/explicação para cálculo de especialização, participação e densidade

\begin{tabular}{|c|c|c|}
\hline $\begin{array}{c}\text { Quociente locacional } \\
\text { (Especialização) }\end{array}$ & $\begin{array}{c}\text { Participação relativa } \\
\text { (Participação) }\end{array}$ & Densidade \\
\hline $\mathrm{QL}=\frac{E_{i j}}{E_{j}} / \frac{E_{i n}}{E_{n}}$ & $\mathrm{PR}=\frac{E_{i j}}{E_{i n}}$ & $\begin{array}{c}\text { Mínimo de 10 de empresas na divisão da } \\
\text { CNAE e mínimo de } 10 \text { empresas em atividades } \\
\text { associadas }\end{array}$ \\
\hline
\end{tabular}

Fonte: Elaboração própria com base em Britto e Albuquerque (2002).

Em que, $\boldsymbol{E}_{i j}=$ emprego do setor i, no município j; $\boldsymbol{E}_{\boldsymbol{j}}=$ emprego total no município j; $\boldsymbol{E}_{\boldsymbol{i n}}=$ emprego do setor i no estado de SC; $\boldsymbol{E}_{\boldsymbol{n}}=$ emprego total no estado de SC; QL = Quociente Locacional; PR = Participação Relativa.

O primeiro passo foi calcular o QL para cada um dos 295 municípios catarinenses, considerando as 24 divisões da indústria de transformação da CNAE, conforme Quadro 4.

Quadro 4 - Divisões da Tabela CNAE utilizadas no estudo

\begin{tabular}{|c|l|}
\hline Divisão & \multicolumn{1}{|c|}{ Descrição } \\
\hline 10 & Fabricação de produtos alimentícios \\
\hline 11 & Fabricação de bebidas \\
\hline 12 & Fabricação de produtos do fumo \\
\hline 13 & Fabricação de produtos têxteis \\
\hline 14 & Confecções de artigo do vestuário e acessórios \\
\hline 15 & Preparação de couros e fabricação de artefatos de couro, artigos para viagem e calçados \\
\hline 16 & Fabricação de produtos de madeira \\
\hline 17 & Fabricação de celulose, papel e produtos de papel \\
\hline 18 & Impressão e reprodução de gravações \\
\hline 19 & Fabricação de coque, de produtos derivados do petróleo e de biocombustíveis \\
\hline 20 & Fabricação de produtos químicos \\
\hline 21 & Fabricação de produtos farmoquímicos e farmacêuticos \\
\hline 22 & Fabricação de produtos de borracha e de material plástico \\
\hline 23 & Fabricação de produtos minerais não metálicos \\
\hline 24 & Metalurgia \\
\hline 25 & Fabricação de produtos de metal, exceto máquinas e equipamentos \\
\hline 26 & Fabricação de equipamentos de informática, produtos eletrônicos e ópticos \\
\hline 27 & Fabricação de máquinas, aparelhos e materiais ecléticos \\
\hline 28 & Fabricação de máquinas e equipamentos \\
\hline 29 & Fabricação de veículos automotores, reboques e carrocerias \\
\hline 30 & Fabricação de outros equipamentos de transporte, exceto veículos automotores \\
\hline 31 & Fabricação de móveis \\
\hline 32 & Fabricação de produtos diversos \\
\hline 33 & Manutenção, reparação e instalação de máquinas e equipamentos \\
\hline
\end{tabular}

Fonte: IBGE (s.d.). 
O segundo passo foi selecionar os pares de municípios-divisões que apresentaram QL>3. Em seguida, foi calculada a PR dos municípios-divisões selecionados. Foram então selecionados aqueles que apresentaram $P R>10$. Na etapa seguinte, foram identificados o número mínimo de 10 estabelecimentos da divisão e o número mínimo de 10 estabelecimentos em atividades relacionadas (essas atividades foram identificadas nas classes da tabela CNAE). Esses passos, além de seguirem o estabelecido por Britto e Albuquerque (2002), são também indicados por Olivares e Dacol (2014), pois um elevado QL pode ocorrer devido à presença de uma única grande indústria em determinado município, ou ainda porque a indústria local apresenta baixa densidade. Assim, é necessário verificar, em cada divisão industrial, a participação do município em relação à região padrão que está sendo utilizada (estado de Santa Catarina) e identificar se há número significativo de empresas agrupadas no município, atuando no segmento.

Para calcular a densidade, considerou-se o número mínimo de 10 empresas na divisão e 10 empresas nas atividades associadas. Como atividades correlatas, foram consideradas: (i) fabricação de máquinas e equipamentos para as indústrias de alimentos, bebidas e fumo; (ii) representantes comerciais e agentes do comércio de produtos alimentícios, bebidas e fumo; (iii) comércio atacadista de carnes, produtos da carne e pescado; (iv) comércio atacadista especializado em produtos alimentícios não especificados anteriormente; (v) comércio varejista de mercadorias em geral, com predominância de produtos alimentícios - hipermercados e supermercados; (vi) comércio varejista de mercadorias em geral, com predominância de produtos alimentícios - minimercados, mercearias e armazéns.

\section{RESULTADOS E DISCUSSÃO}

Para identificar os clusters industriais presentes no estado de Santa Catarina, foram utilizados: (i) o QL, para visualizar a especialização; (ii) a PR, para visualizar a relevância; (iii) o número de estabelecimentos presentes na divisão de cada indústria de transformação, bem como em atividades associadas, para verificar a relevância. Na Tabela 1, estão apresentados os critérios utilizados, os quais possibilitaram a identificação dos clusters catarinenses e dos municípios onde os clusters foram identificados, nas relativas atividades econômicas.

Tabela 1 - Identificação dos clusters industriais catarinenses

\begin{tabular}{|c|c|c|c|c|}
\hline \multirow{2}{*}{ Divisão CNAE } & \multirow{2}{*}{\begin{tabular}{|c|} 
Critério $1^{*}$ \\
Clusters \\
\end{tabular}} & \multirow{2}{*}{$\begin{array}{l}\text { Critério } 2^{* *} \\
\text { Clusters } \\
\end{array}$} & \multicolumn{2}{|c|}{ Critério $3 * * *$} \\
\hline & & & Clusters & Município \\
\hline Fabricação de produtos alimentícios & 41 & 1 & 1 & Chapecó \\
\hline Fabricação de bebidas & 16 & 2 & 0 & \\
\hline Fabricação de produtos do fumo & 9 & 2 & 0 & \\
\hline Fabricação de produtos têxteis & 20 & 2 & 2 & $\begin{array}{l}\text { Blumenau e } \\
\text { Brusque }\end{array}$ \\
\hline $\begin{array}{l}\text { Confecção de artigos do vestuário e } \\
\text { acessórios }\end{array}$ & 52 & 0 & 0 & \\
\hline $\begin{array}{l}\text { Preparação de couros e fabricação de } \\
\text { artefatos de couro, artigos para viagem e } \\
\text { calçados }\end{array}$ & 11 & 2 & 1 & $\begin{array}{l}\text { São João } \\
\text { Batista }\end{array}$ \\
\hline Fabricação de produtos de madeira & 65 & 1 & 1 & Caçador \\
\hline
\end{tabular}




\begin{tabular}{|c|c|c|c|c|}
\hline \multirow{2}{*}{ Divisão CNAE } & \multirow{2}{*}{\begin{tabular}{|c|} 
Critério $1 *$ \\
Clusters \\
\end{tabular}} & \multirow{2}{*}{\begin{tabular}{|c|} 
Critério $2^{* *}$ \\
Clusters \\
\end{tabular}} & \multicolumn{2}{|c|}{ Critério $3 * * *$} \\
\hline & & & Clusters & Município \\
\hline $\begin{array}{l}\text { Fabricação de celulose, papel e produtos de } \\
\text { papel }\end{array}$ & 28 & 0 & 0 & \\
\hline Impressão e reprodução de gravações & 7 & 1 & 0 & \\
\hline $\begin{array}{l}\text { Fabricação de coque, de produtos derivados } \\
\text { do petróleo e de biocombustíveis }\end{array}$ & 4 & 3 & 0 & \\
\hline Fabricação de produtos químicos & 18 & 0 & 0 & \\
\hline $\begin{array}{l}\text { Fabricação de produtos farmoquímicos e } \\
\text { farmacêuticos }\end{array}$ & 6 & 1 & 0 & \\
\hline $\begin{array}{l}\text { Fabricação de produtos de borracha e de } \\
\text { material plástico }\end{array}$ & 16 & 0 & 0 & \\
\hline $\begin{array}{l}\text { Fabricação de produtos de minerais não } \\
\text { metálicos }\end{array}$ & 22 & 1 & 1 & Criciúma \\
\hline Metalurgia & 11 & 1 & 1 & Joinville \\
\hline $\begin{array}{l}\text { Fabricação de produtos de metal, exceto } \\
\text { máquinas e equipamentos }\end{array}$ & 19 & 0 & 0 & \\
\hline $\begin{array}{l}\text { Fabricação de equipamentos de informática, } \\
\text { produtos eletrônicos e ópticos }\end{array}$ & 13 & 1 & 1 & São José \\
\hline $\begin{array}{l}\text { Fabricação de máquinas, aparelhos e } \\
\text { materiais elétricos }\end{array}$ & 14 & 2 & 2 & \begin{tabular}{|c|} 
Jaraguá do \\
Sul e Joinville
\end{tabular} \\
\hline Fabricação de máquinas e equipamentos & 14 & 1 & 1 & Joinville \\
\hline $\begin{array}{l}\text { Fabricação de veículos automotores, } \\
\text { reboques e carrocerias }\end{array}$ & 12 & 1 & 0 & \\
\hline $\begin{array}{l}\text { Fabricação de outros equipamentos de } \\
\text { transporte, exceto veículos automotores }\end{array}$ & 6 & 1 & 1 & Navegantes \\
\hline Fabricação de móveis & 32 & 1 & 1 & $\begin{array}{c}\text { São Bento do } \\
\text { Sul }\end{array}$ \\
\hline Fabricação de produtos diversos & 9 & 1 & 0 & \\
\hline $\begin{array}{l}\text { Manutenção, reparação e instalação de } \\
\text { máquinas e equipamentos }\end{array}$ & 19 & 0 & 0 & \\
\hline Total & 464 & 25 & 13 & \\
\hline
\end{tabular}

${ }^{*} \mathrm{QL}>3 ;{ }^{* *} \mathrm{QL}>3$ e $\mathrm{PR}>10 \% ;{ }^{* * *}$ Critérios 1 e 2, mais de 10 estabelecimentos na divisão e mais de 10 em atividades associadas.

Fonte: Os próprios autores, 2020.

Atendendo ao critério 1, foram encontradas 464 aglomerações, indicando que todas as divisões da indústria de transformação apresentaram aglomerações. Isto é, na relação entre município e atividade desenvolvida, foram encontradas 464 especializações, consideradas como evidências para a formação de clusters (BRITTO; ALBUQUERQUE, 2002). Esse número também indica que vários municípios, se não todos, possuem alguma especialização produtiva. A divisão "fabricação de produtos de madeira" foi a que apresentou o maior número de aglomerações (65), seguida pela "confecção de artigos do vestuário e acessórios" (52) e pela "fabricação de produtos alimentícios" (41).

Em seguida, foram eliminados os municípios que apresentaram participação no total do emprego do estado, em cada divisão da indústria de transformação, igual ou menor que 10\%. Com isso, restaram 25 aglomerações produtivas, tendo sido eliminados os municípios 
que apresentaram reduzida participação no setor produtivo, mesmo sendo identificados como especializados ( $Q \mathrm{~L}>3$ ).

Entendendo que, para ser considerada um cluster, a aglomeração deve possuir uma densidade mínima, quanto ao número de empresas (BRITTO; ALBUQUERQUE, 2002), foram selecionados somente aqueles municípios que atenderam também ao terceiro critério, restando então 13 clusters. Pelo fato de o município de Joinville ter apresentado aglomerações em três atividades industriais, e por essas estarem ligadas de alguma forma, optou-se por considerar as três como um único cluster, conforme apresentado na Tabela 2. Desta forma, mantendo atenção a uma sofisticada progressão de critérios (BRITTO; ALBUQUERQUE, 2002), foram identificados 11 clusters industriais catarinenses.

Os clusters catarinenses estão presentes em nove das vinte e cinco microrregiões. As microrregiões de Joinville e Blumenau concentram dois clusters cada uma. As microrregiões de Chapecó, Joaçaba, São Bento do Sul, Itajaí, Tijuca, Florianópolis e Criciúma possuem um cluster cada uma. A Figura 1 mostra os municípios e os respectivos clusters identificados.

Figura 1- Distribuição dos clusters industriais pelo estado

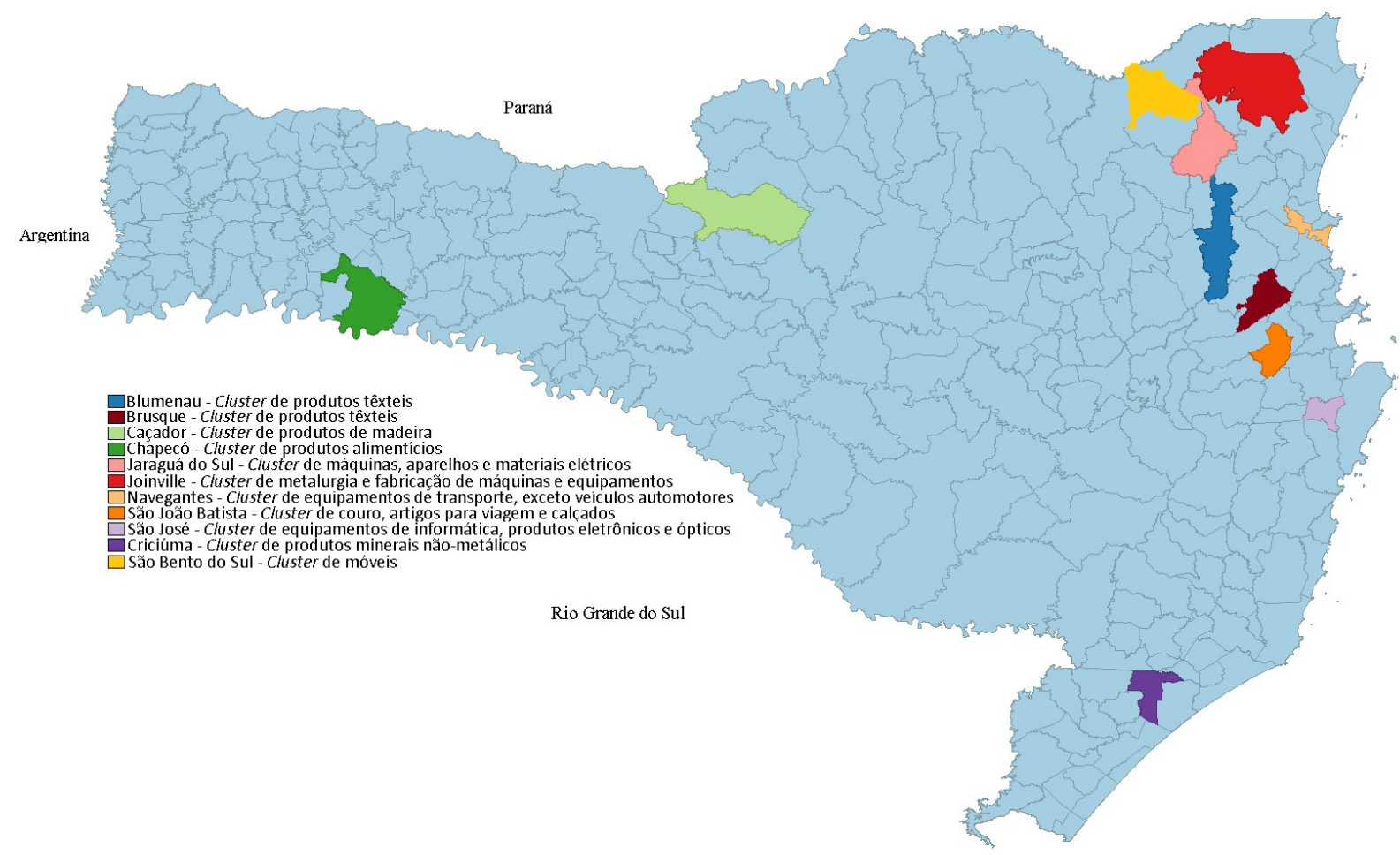

Fonte: Os próprios autores, 2020.

A maior parte dos clusters - Blumenau, Brusque, Jaraguá do Sul, Joinville, São Bento, Navegantes, São João Batista, São José - está concentrada na região litorânea nordeste, que apresenta maior desenvolvimento industrial no estado catarinense. Viana e Hoffmann (2009) já indicaram que os municípios de Jaraguá do Sul, Joinville e São Bento do Sul destacam-se pela forte estrutura industrial que possuem. Os municípios de Joinville e Blumenau foram também identificados por Bittencourt e Campos (2009) como líderes na indústria de transformação em suas microrregiões, sendo estas as mais ricas do estado catarinense.

Britto e Albuquerque (2002) haviam indicando, ainda, a formação de clusters têxteisvestuário, sendo um no município de Blumenau e outro no município de Brusque. Rosa (2015) 
apontou São João Batista como uma região referência no setor de calçados, contando com elevado número de micro e pequenas empresas, desde a década de 1980. Assim, identificar que a maior parte dos clusters está presente mais no litoral nordeste de Santa Cataria era algo esperado na pesquisa, mas não se sabia ao certo quais seriam os municípios.

Um pouco mais distantes da concentração de clusters na região litorânea noroeste do estado, outros foram identificados nos municípios de Chapecó, Caçador e Criciúma. Bittencourt e Campos (2009) apontaram o município de Criciúma como um centro produtor de cerâmica de revestimento, com a existência de grandes empresas, mas também densa aglomeração de empresas de pequeno porte. Esses mesmos autores apontaram Chapecó como sede de grandes empresas exportadoras de carne. No caso de Chapecó, as duas principais empresas que trabalham com alimentos são a Brasil Foods e a Aurora Alimentos. Mas existe uma série de empresas de pequeno porte que estão inseridas na indústria alimentícia (BITTENCOURT; CAMPOS, 2009) e que compõem e movimentam o cluster. Bittencourt e Campos (2009) indicam também que, em Caçador, cerca de 200 empresas foram um aglomerado com especialização madeireira.

Os onze clusters identificados no território de Santa Catarina são de atividades produtivas distintas, enfatizando a produção e a diversificação industrial no estado. Ao mesmo tempo em que cada cluster conta com uma ou mais grandes empresas, há concentração de empresas de pequeno que desenvolvem atividades específicas do cluster ou atividades associadas.

A partir dos dados extraídos da RAIS, foram identificadas as informações constantes na Tabela 2. Nota-se que todos os clusters apresentam QL acima de 3, apontando para a existência de ao menos uma concentração produtiva. Conforme destacam João e Olivares (2014), um QL elevado indica que, em determinada região, uma ou mais atividades produtivas predominam na estrutura de produção local. Também, indica que determina indústria apresenta uma especialização quanto à estrutura de produção local (REZENDE; CAMPOLINA; PAIXÃO, 2012).

Quanto aos QLs, verifica-se que houve uma aproximação entre eles, em relação ao valor encontrado, com exceção do cluster de couro, artigos para viagem e calçados, que ficou com valor bem superior. Isso indica que, no município de São João Batista, há uma forte concentração de empresas atuando especificamente na atividade de couros, artigos para viagem e calçados. O município de São João Batista foi indicado como um centro especializado, movido por atividades ligadas a calçados, mostrando-se como um caso específico que pode ser analisado de diferentes formas (ROSA, 2015). São João Batista, segundo o IBGE (s.d.), possui 37.434 habitantes, considerado o menor entre os onze identificados com formação de clusters em Santa Catarina. 


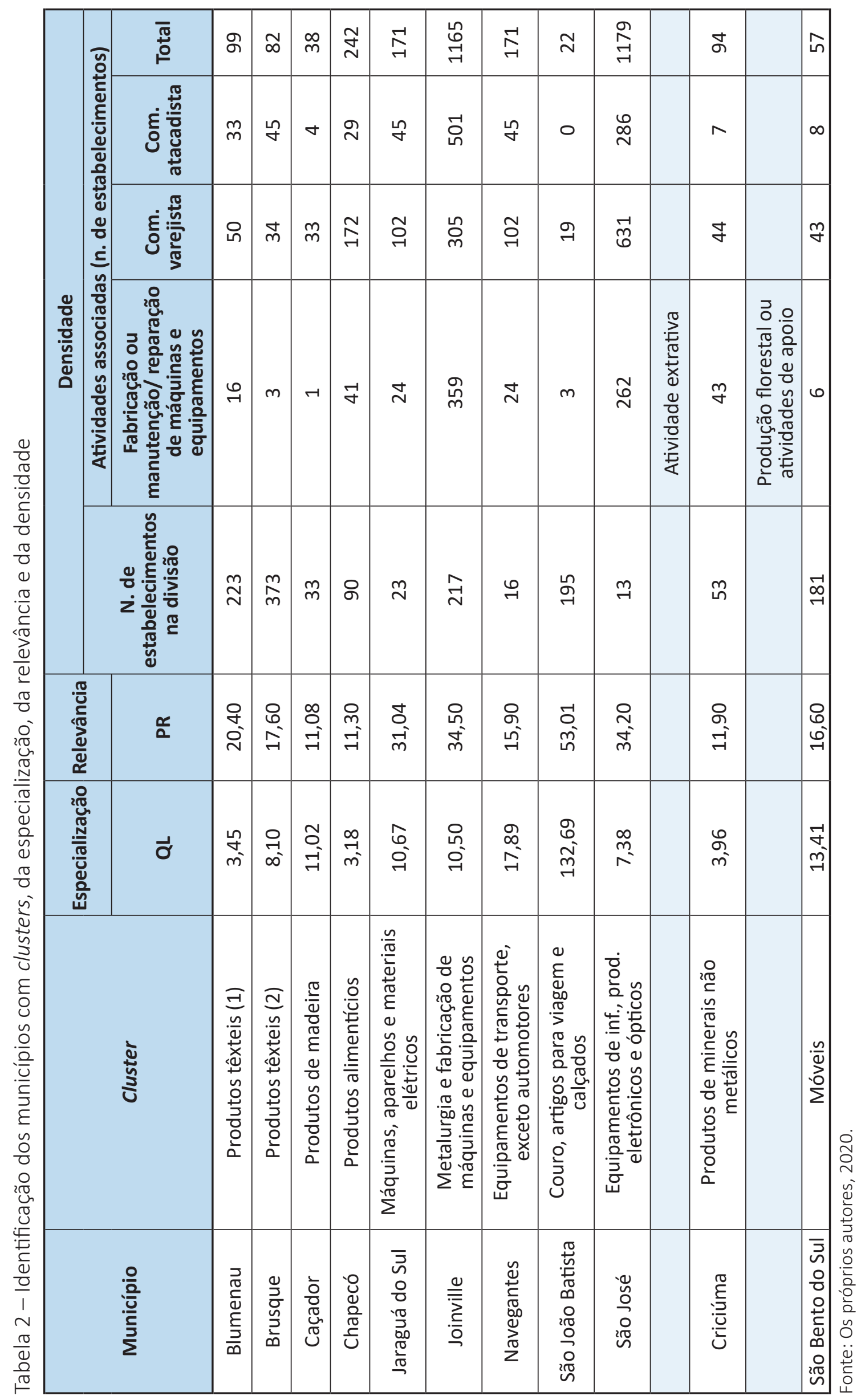


De modo a identificar o quão importante é cada cluster ante a região de referência, neste caso, o estado de Santa Catarina, procedeu-se o cálculo da participação relativa (PR). Percebese que os onze clusters identificados apresentam, além de especialização - QL>3 -, diversos setores produtivos do estado de Santa Catarina. Na sequência, procedeu-se a identificação da quantidade de empresas presentes em cada cluster; isto é, o número de empresas que atuam naquela atividade produtiva, no município onde foi verificada especialização e importância. Quase todos os clusters possuem elevado número de empresas na atividade-base (na divisão). As exceções são os clusters de São José, Navegantes e Jaraguá do Sul, respectivamente, com 13,16 e 23.

Referente à quantidade de estabelecimentos concentrados na atividade principal, o destaque é o cluster têxtil de Brusque, que, ante os onze clusters, aglomera 26,3\%, seguido pelo cluster têxtil de Blumenau, com 15,7\%, e pelo cluster metalúrgico e fabricação de máquinas e equipamentos de Joinville, com 15,3\%. Ainda, destacam-se os clusters de couro, artigos para viagem e calçados, de São João Batista, com 13,8\% dos estabelecimentos; e os de móveis, de São Bento do Sul, com 12,8\%.

Os onze clusters são formados, prioritariamente, por micro e pequenas empresas, conforme Tabela 3. Percebe-se que 40\% dos estabelecimentos possuem até 4 empregados, $19 \%$ possuem de 5 a 9 empregados, 16\% possuem de 10 a 19 empregados e $12 \%$ possuem de 20 a 49 empregados. Os atores que constituem um cluster são os responsáveis por seu desenvolvimento e pela forma de atuação das empresas. Formados por empresas de pequeno porte, os clusters possibilitam a troca de informações e a economia de escala, ao mesmo tempo que apresentam oportunidades de trabalho para os trabalhadores e, também, para as novas empresas (PIEKARSKI; TORKOMIAN, 2005).

Por outro lado, todos os clusters identificados possuem ao menos uma grande empresa na sua composição. Tal realidade, aliada à predominância de micro e pequenas empresas, demonstra a complementariedade e as oportunidades de ganhos mútuos na cadeia produtiva de cada cluster. Por exemplo, no cluster de produtos alimentícios, são 80 empresas que possuem até 49 funcionários, sendo que essas geram 802 empregos, enquanto as 5 empresas que possuem mais de 500 funcionários geram 11.505 empregos. Outro exemplo, o cluster de produtos têxteis de Blumenau, onde as 203 empresas com até 49 funcionários geram 1.709 empregos, enquanto as 6 empresas com mais de 500 funcionários geram 7.435 empregos. 


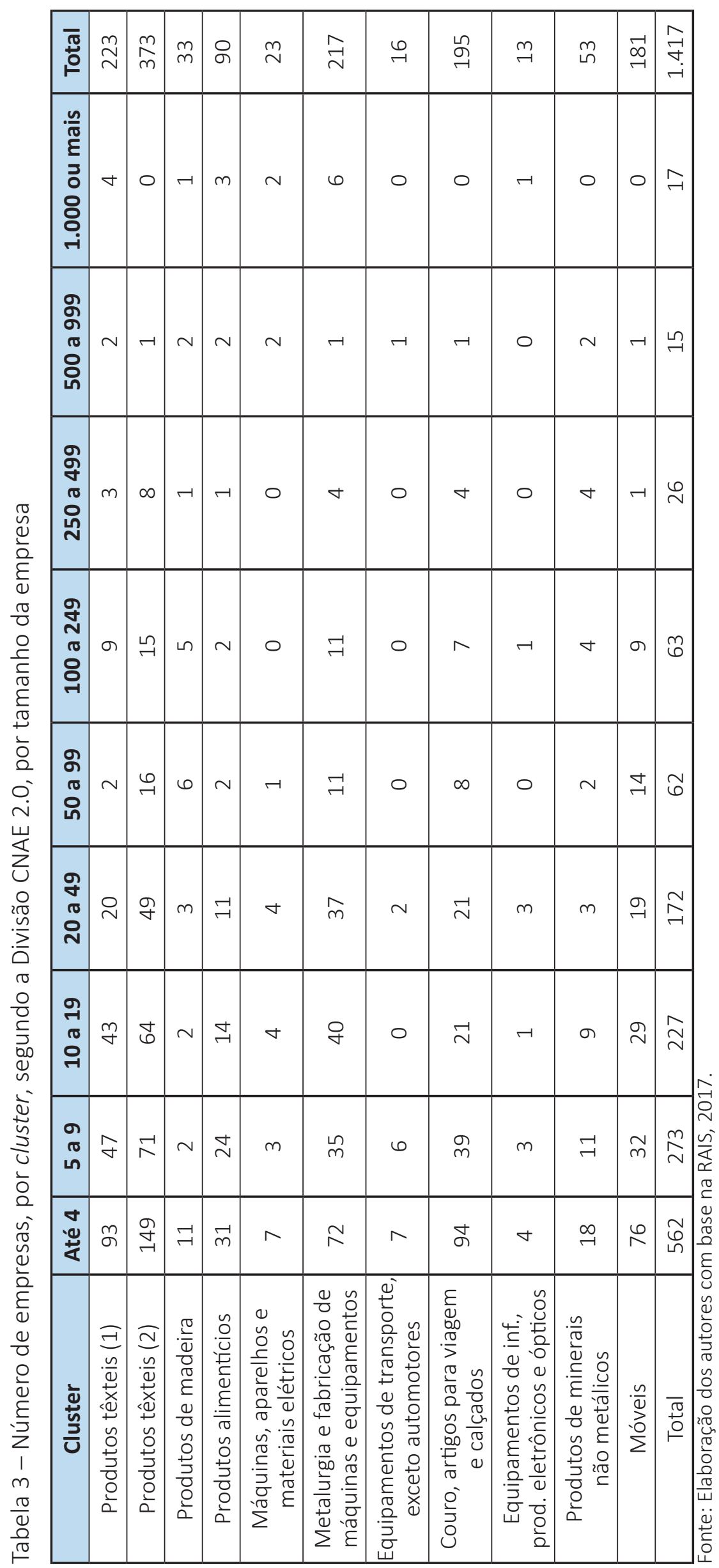


Como indicam Bittencourt e Campos (2009), a estrutura econômica catarinense é baseada na atuação de micro e pequenas empresas, junto às grandes indústrias existentes. Nos municípios onde os clusters foram identificados, existe ao menos uma grande empresa (com mais de 500 funcionários). Contudo o destaque é a presença de micro, pequenas e médias empresas que desempenham também importante papel na economia (GEROLAMO et al., 2008). Algumas barreiras de mercado dificilmente seriam vencidas por uma empresa de pequeno porte se esta estivesse atuando sozinha; mas, ao atuar em um cluster, os vínculos estabelecidos com outras empresas possibilitam vencer tais barreiras (CROCCO et al., 2003).

Referente à escolaridade dos trabalhadores, a Tabela 4 indica que todos os clusters apresentam maior concentração de trabalhadores com ensino médio. Os clusters de metalurgia, fabricação de máquinas e equipamentos, de máquinas, aparelhos e materiais elétricos e de produtos de minerais não metálicos concentram mais de $50 \%$ dos trabalhadores com formação de ensino médio. A formação em seguida, com maior concentração de trabalhadores, é o fundamental completo, em que aparecem sete clusters. Isso mostra que a maior parte dos trabalhadores, dos onze clusters, possui formação mediana. 


\begin{tabular}{|c|c|c|c|c|c|c|c|c|c|c|c|}
\hline \begin{tabular}{l} 
윰 \\
$\frac{\pi}{0}$ \\
\multirow{2}{0}{} \\
8
\end{tabular} & $\mid \begin{array}{l}-1 \\
0 \\
0\end{array}$ & $\begin{array}{l}-1 \\
0 \\
0\end{array}$ & $\mid \begin{array}{l}1 \\
0 \\
0\end{array}$ & $\begin{array}{l}8 \\
0 \\
0\end{array}$ & $\begin{array}{l}8 \\
0\end{array}$ & $\begin{array}{l}\tilde{O} \\
\tilde{0} \\
\sigma^{\prime}\end{array}$ & 8: & 8. & 8. & $\begin{array}{l}8 \\
0\end{array}$ & 이 \\
\hline 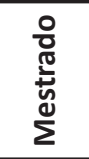 & $\mid \begin{array}{l}m \\
0 \\
0\end{array}$ & $\left|\begin{array}{l}0 \\
0 \\
0 \\
0\end{array}\right|$ & $\mid \begin{array}{l}0 \\
0 \\
0\end{array}$ & $\begin{array}{l}n \\
0 \\
0 \\
0\end{array}$ & $\begin{array}{l}\text { Iี } \\
\text { o }\end{array}$ & 今̈ & 경 & 8: & $\begin{array}{l}\stackrel{+}{*} \\
0^{\circ}\end{array}$ & $\begin{array}{l}m \\
0 \\
0\end{array}$ & $\mid \begin{array}{l}7 \\
0 \\
0\end{array}$ \\
\hline 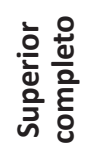 & $\begin{array}{c}+ \\
\infty \\
\infty\end{array}$ & \begin{tabular}{|c|c}
$\stackrel{n}{n}$ \\
\end{tabular} \mid & $\left|\begin{array}{l}0 \\
6 \\
0^{-}\end{array}\right|$ & $\begin{array}{l}0 \\
m \\
\varphi^{-}\end{array}$ & $\begin{array}{l}\stackrel{m}{\Omega} \\
\infty\end{array}$ & $\begin{array}{l}\hat{b} \\
\stackrel{n}{\rightarrow}\end{array}$ & $\begin{array}{l}\underset{\sim}{*} \\
\text {. }\end{array}$ & $\begin{array}{l}\infty \\
\infty \\
i\end{array}$ & $\begin{array}{l}\text { ' } \\
\text { m} \\
m\end{array}$ & $\begin{array}{l}\frac{n}{\kappa} \\
\sigma\end{array}$ & 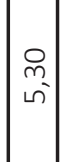 \\
\hline 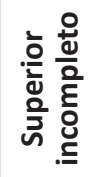 & \begin{tabular}{|l|}
$\infty$ \\
$\infty$ \\
$m$
\end{tabular} & $\mid \begin{array}{l}\overrightarrow{-1} \\
\sim \\
\sim\end{array}$ & $\begin{array}{l}\stackrel{\bigcirc}{\circ} \\
+\end{array}$ & 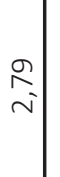 & $\stackrel{m}{\stackrel{n}{N}}$ & $\underset{i}{\stackrel{N}{N}}$ & $\underset{+}{\stackrel{\sim}{\sim}}$ & 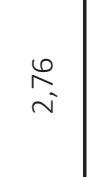 & \begin{tabular}{l}
$\mathscr{8}$ \\
$\stackrel{-}{7}$ \\
\multirow{r}{*}{}
\end{tabular} & 号 & $\stackrel{\stackrel{\sim}{\sim}}{\stackrel{\sim}{\sim}}$ \\
\hline 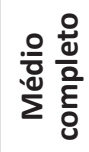 & $\begin{array}{l}\vec{\infty} \\
\hat{n} \\
\hat{m}\end{array}$ & $\begin{array}{l}\infty \\
\sim \\
\infty \\
m \\
m\end{array}$ & $\left|\begin{array}{c}\stackrel{\searrow}{\sim} \\
\infty \\
\sim \\
\sim\end{array}\right|$ & $\begin{array}{l}n \\
n \\
n \\
m\end{array}$ & 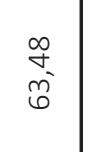 & $\begin{array}{l}\text { ô } \\
\text { ì }\end{array}$ & \begin{tabular}{l}
$\hat{\infty}$ \\
\multirow{y}{*}{} \\
\multirow{y}{*}{}
\end{tabular} & $\begin{array}{l}\underset{f}{N} \\
\vec{y}\end{array}$ & $\begin{array}{l}\underset{7}{\sim} \\
\underset{y}{\sim}\end{array}$ & 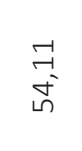 & $\left|\begin{array}{l}\tau \\
6 \\
0 \\
\tilde{m}\end{array}\right|$ \\
\hline 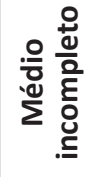 & $\begin{array}{l}\infty \\
0 \\
m \\
\end{array}$ & $\left|\begin{array}{c}\stackrel{m}{m} \\
\stackrel{m}{\sim}\end{array}\right|$ & $\mid \begin{array}{l}\infty \\
\hat{0} \\
0 \\
-1\end{array}$ & $\begin{array}{l}\infty \\
\infty \\
\rightarrow \\
\rightarrow\end{array}$ & $\begin{array}{l}\stackrel{\omega}{\omega} \\
\infty_{0}^{-}\end{array}$ & $\begin{array}{l}\hat{a} \\
\text { ô }\end{array}$ & $\begin{array}{l}\text { న్ } \\
\text { ò } \\
-1\end{array}$ & $\begin{array}{l}\stackrel{0}{ } \\
\text { ñ } \\
\sim\end{array}$ & $\begin{array}{l}\vec{\infty} \\
n^{-}\end{array}$ & $\begin{array}{l}8 \\
\stackrel{-}{y} \\
\vec{r}\end{array}$ & $\left|\begin{array}{l}- \\
\vec{z} \\
\sigma\end{array}\right|$ \\
\hline 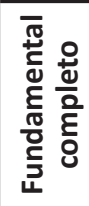 & $\begin{array}{l}m \\
\stackrel{n}{-} \\
\sim\end{array}$ & 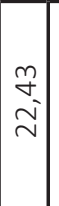 & 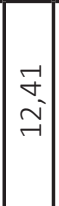 & 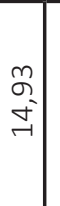 & $\underset{\infty}{\stackrel{\Xi}{\Delta}}$ & 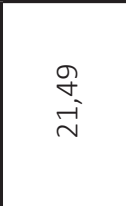 & $\begin{array}{l}\overrightarrow{1} \\
\infty \\
\rightarrow\end{array}$ & $\begin{array}{l}m_{m} \\
\underbrace{-}\end{array}$ & 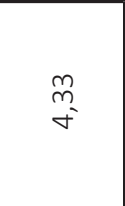 & $\begin{array}{l}\stackrel{\infty}{\infty} \\
\infty^{-}\end{array}$ & $\begin{array}{l}\stackrel{\sim}{\sim} \\
\stackrel{\sim}{\sim}\end{array}$ \\
\hline 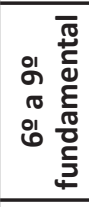 & $\mid \begin{array}{l}\stackrel{+}{n} \\
\stackrel{7}{ت}\end{array}$ & $\begin{array}{l}\overrightarrow{\hat{n}} \\
\sigma\end{array}$ & $\left|\begin{array}{l}m \\
\stackrel{i}{\sim}\end{array}\right|$ & 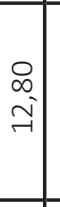 & 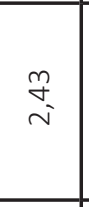 & $\begin{array}{l}\stackrel{\infty}{\infty} \\
i \\
i\end{array}$ & 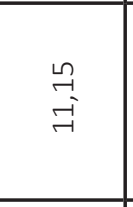 & $\begin{array}{l}\stackrel{n}{m} \\
\stackrel{m}{r}\end{array}$ & $\begin{array}{l}m \\
\infty \\
0 \\
0\end{array}$ & 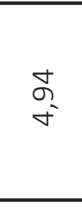 & $\left|\begin{array}{c}\tilde{N} \\
\tilde{m} \\
\vec{\eta}\end{array}\right|$ \\
\hline 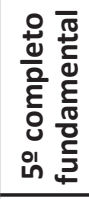 & $\begin{array}{l}\underset{0}{0} \\
\sim \\
\forall\end{array}$ & $\begin{array}{l}ت \\
\vec{G} \\
\dot{n}\end{array}$ & $\stackrel{\simeq}{\sim}$ & $\begin{array}{c}\infty \\
m \\
m \\
m\end{array} \mid$ & $\underset{\stackrel{d}{\sim}}{\stackrel{0}{0}}$ & $\begin{array}{l}? \\
\text { o }\end{array}$ & $\begin{array}{l}\mathscr{8} \\
\text { o. }\end{array}$ & $\begin{array}{l}\tilde{m} \\
m \\
m\end{array}$ & $\stackrel{m}{\stackrel{7}{0}}$ & $\begin{array}{l}m \\
\stackrel{m}{m}\end{array}$ & $\left|\begin{array}{l}\hat{a} \\
\text { ñ. }\end{array}\right|$ \\
\hline 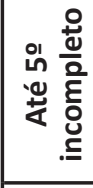 & 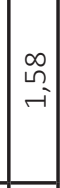 & $\stackrel{\substack{n \\
\sim}}{\sim}$ & 염 & $\begin{array}{l}\stackrel{\nabla}{+} \\
\stackrel{+}{*}\end{array}$ & $\stackrel{\stackrel{\sim}{n}}{\stackrel{0}{0}}$ & $\stackrel{\stackrel{n}{m}}{m_{0}^{\prime}}$ & $\stackrel{n}{\sim}$ & $\begin{array}{l}8 \\
\stackrel{8}{0}\end{array}$ & $\underset{-}{\stackrel{\Delta}{-}}$ & $\begin{array}{l}\stackrel{n}{\stackrel{n}{r}} \\
\rightarrow\end{array}$ & $\left|\begin{array}{l}n \\
\infty \\
\sim \\
\sim\end{array}\right|$ \\
\hline $\begin{array}{l}\stackrel{8}{\mathbb{J}} \\
\frac{0}{0} \\
\frac{5}{5} \\
\frac{5}{\pi} \\
\frac{5}{4}\end{array}$ & $\begin{array}{l}m \\
- \\
0 \\
0\end{array}$ & \begin{tabular}{l}
\multirow{2}{*}{} \\
0 \\
0
\end{tabular} & $\begin{array}{l}0 \\
0 \\
0 \\
0\end{array}$ & $\stackrel{n}{\wedge}$ & $\begin{array}{l}-1 \\
0 \\
0\end{array}$ & $\begin{array}{l}\text { o } \\
\text { o. }\end{array}$ & $\begin{array}{l}-7 \\
\text { ㄱ. }\end{array}$ & ने & $\begin{array}{l}\text { Oे } \\
\text { - }\end{array}$ & $\begin{array}{l}\text { 足 } \\
\text { o. }\end{array}$ & $\left|\begin{array}{l}7 \\
7 \\
0\end{array}\right|$ \\
\hline$\frac{\grave{\Xi}}{\stackrel{\Xi}{\Xi}}$ & 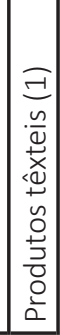 & 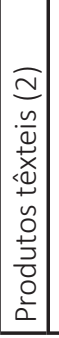 & 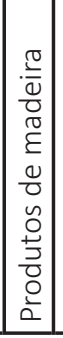 & 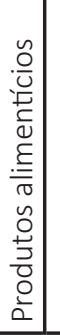 & 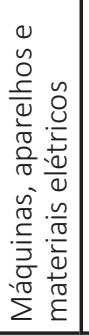 & 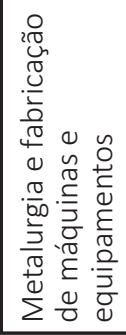 & 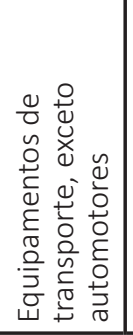 & 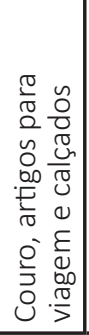 & 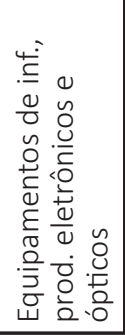 & 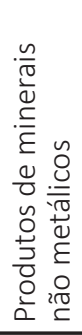 & 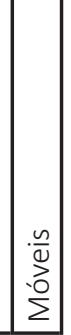 \\
\hline
\end{tabular}


Quanto ao grau de instrução dos trabalhadores, apontam-se outros aspectos relevantes. Os clusters (i) metalurgia e fabricação de máquinas e equipamentos, (ii) máquinas, aparelhos e materiais elétricos, (iii) equipamentos de informática, produtos eletrônicos e ópticos concentram mais trabalhadores com maior grau de instrução e menos trabalhadores com menor grau de instrução. Esses clusters estão entre aqueles com menores porcentagens de trabalhadores analfabetos e com fundamental completo, e com as maiores porcentagens de trabalhadores com ensino médio completo, superior completo e mestrado. Então, esses clusters, embora possuam atividades que podem ser desenvolvidas por trabalhadores com baixo grau de educação formal, precisam também de mão de obra especializada, com maior grau de formação.

Outros clusters contam com mais trabalhadores que possuem menores graus de instrução e menos trabalhadores com maiores graus de instrução, como é o caso de: (i) produtos alimentícios; (ii) produtos de madeira; (iii) móveis. Nestes, as maiores porcentagens de trabalhadores encontram-se nas faixas com 5음 ano do fundamental incompleto e do 6으 ao 9o ano do fundamental. Além destes três clusters citados, o de couro, artigos para viagem e calçados concentra as menores porcentagens de trabalhadores com ensino médio completo, superior incompleto, superior completo e mestrado. Tais resultados indicam que esses clusters suprem suas necessidades, com mão de obra com baixa qualificação.

Segundo Iglioni (2001), a ligação com universidades é uma das características de um cluster. Neste sentido, verifica-se que, nos municípios onde os clusters foram identificados, existem universidades, sejam públicas, sejam privadas, presenciais ou a distância. Não se buscou verificar a existência de ligações entre o cluster e as universidades, contudo entende-se que a existência de universidades nos municípios onde os clusters foram identificados possibilita a interação.

Buscou-se analisar as características dos clusters identificados, com algumas tipologias de clusters. Sem esgotar o debate, pois não foi analisado individualmente cada um dos clusters, verificase que, em comparação com as seis tipologias organizadas por Rissete, Macedo e Meiners (2003), os clusters industriais catarinenses identificados apresentam aspectos que os caracterizam como "informais", podendo também ser "organizados". Isso porque em torno de $74,9 \%$ das empresas presentes nas atividades diretas do cluster são micro. Outras 16,5\% são pequenas, 6,3\% são médias e 2,3\% são grandes. Contribui ainda para essa classificação o fato do nível "baixo" ou "médio" de inovação presente nos clusters, bem como o "baixo" e "médio" nível de especialização encontrado e, ainda o elevado nível de emprego existente. Neste sentido, Altemburg e Meyer-Stamer (1999) apontaram que, de modo geral, os clusters presentes na América Latina apresentam falta de capacidade de inovar, como também baixo grau de especialização e cooperação.

\section{CONSIDERAÇÕES FINAIS}

A literatura sobre clusters industriais tem discutido a importância desses agrupamentos e da localização geográfica das empresas no desenvolvimento local e regional. As vantagens que os clusters podem gerar às empresas que deles participam atraem os olhares dos estudiosos que buscam entender os elementos que movem as atividades produtivas. Possíveis vantagens competitivas são também de interesse das empresas que participam ou buscam participar de algum cluster.

Este estudo teve como principal objetivo identificar a existência de clusters industriais na economia catarinense, evidenciando aspectos relacionados à dinâmica produtiva do estado. 
Utilizando a metodologia de Britto e Albuquerque (2002), foram identificados onze clusters industriais catarinenses. Foi possível, também, evidenciar elementos próprios, tais como: tamanho das empresas que formam os clusters, nível educacional dos trabalhadores e algumas características da tipologia. Segundo a tipologia em que os clusters podem ser classificados (informais ou organizados), percebe-se que há possibilidade de avançar em vários aspectos, principalmente no desenvolvimento de tecnologias e capacidade de inovação por parte das empresas. Sobre o tamanho das empresas que compõem os clusters, é importante destacar que esses aglomerados somente existem pela existência das empresas de pequeno porte que estabelecem relações umas com as outras, visto que empresas de grande porte dificilmente apresentam o mesmo espírito de cooperação e competição.

Diante da literatura existente que aponta/discute a existência de alguns clusters específicos no estado de Santa Catarina, mas sem análises mais profundas, este estudo identificou onze clusters industriais a partir de uma metodologia desenvolvida para com essa finalidade. A identificação dos clusters industriais catarinenses possibilita a visualização de elementos que são importantes para os gestores das empresas que os compõem. Ao entenderem a realidade em que suas empresas estão inseridas, estes têm a possibilidade de traçar estratégias acertadas que tragam retorno, de modo a fortalecer seu negócio.

Ao identificar os onze clusters industriais catarinenses, este estudo auxilia os gestores das empresas a compreender as forças econômicas presentes no estado, bem como a refletir para a tomada de decisões. Embora esta pesquisa tenha atingido o objetivo proposto e tenha apresentado contribuições para o campo, não é um fim em si, mesmo porque apresenta limitações. Uma limitação está no fato de não dar conta de estudar os elementos específicos da história de cada cluster identificado. Outra limitação está no fato de não conseguir identificar o quantitativo exato de empresas que constituem cada um dos clusters.

Mesmo diante dessas limitações, o estudo apresenta elementos capazes de avivar a discussão dos temas ligados às atividades produtivas, especialmente no estado de Santa Catarina. Além disso, é possível apontar vários aspectos que podem ser aprofundados em outros estudos. Dois em especial são elencados: (i) sugere-se que pesquisas futuras possam deter-se em analisar características internas de um ou mais clusters identificados, entendendo suas potencialidades, suas fraquezas; (ii) indica-se analisar a relevância que cada um dos clusters industriais identificados tem no desenvolvimento local, bem como na promoção das atividades econômicas.

\section{REFERÊNCIAS}

ALDERETE, M. V.; BACIC, M. J. The impact of brazilian clusters on local development: a propensity score matching approach. Interações, Campo Grande, v. 21, n. 1, p. 173-94, 2020.

ALTEMBURG, T.; MEYER-STAMER, J. How to promote clusters: policy experiences from Latin America. World Development, Amsterdã, v. 27, n. 9, p. 1693-713, 1999.

AMIN, A. Industrial Districts. In: SHEPPARD, E.; BARNES, T. J. (Org.). A companion to economic geography. Oxford: Blackwell Publishing, 2003. p. 149-68.

ANDRADE, G. A. Dinâmica competitiva das micro e pequenas empresas no cluster industrial têxtil-vestuário do Vale do Itajaí-SC. 2002. 141 f. Dissertação (Mestrado em Economia) - Universidade Federal de Santa Catarina, Florianópolis, SC, 2002. 
ANDRIANI, P. et al. Challenging clusters: the prospects and pitfalls of clustering for innovation and economic development. London: Advanced Institute of Management Research, 2005.

ANTUNES-FERREIRA, C.; SANTOS-NATÁRIO, M.; MARTINS-BRAGA, A. Análise e avaliação ao funcionamento dos clusters em Portugal reconhecidos pelo QREN. Economía Sociedad y Territorio, Toluca, v. 18, n. 57, p. 585-620, 2018.

AZIZ, K. A.; NORHASHIM, M. Cluster-based policy making: assessing performance and sustaining competitiveness. Review of Policy Research, [s.l.], v. 25, n. 4, p. 349-75, 2008.

BERGMAN, E.; FESER, E. Industrial and regional clusters: concepts and comparative applications. Michigan: WVU Research Repository, 1999. Disponível em: http://www.rri.wvu.edu/WebBook/Bergman-Feser/ contents.htm. Acesso em: 2 mar. 2019.

BERKECZ-KOVÁCS, L. New trends in the development of hungarian clusters: the case of the Southern Great Plain region. Regional Statistics, Budapest, v. 8, n. 1, p. 78-95, 2018.

BITTENCOURT, P. F.; CAMPOS, R. R. Diversificação de estruturas industriais localizadas: um estudo de caso para o estado de Santa Catarina. Revista de Economia, Curitiba, v. 35, n. 2, p. 33-59, 2009.

BRAUNERHJELM, P.; CARLSSON, B. Industry clusters in Ohio and Sweden, 1975-1995. Small Business Economics, New York, v. 12, n. 4, p. 279-93, 1999.

BRESCHI, S. Knowledge spillovers and local innovation systems: a critical survey. Industrial and Corporate Change, Oxônia, v. 10, n. 4, p. 975-1005, 2001.

BRITTO, J.; ALBUQUERQUE, E. M. Clusters industriais na economia brasileira: uma análise exploratória a partir de dados da RAIS. Estudos Econômicos, São Paulo, v. 32, n. 1, p. 71-102, 2002.

CAMPOS, R. R.; NICOLAU, J. A.; CÁRIO, S. A. F. Cluster e capacitação tecnológica: a experiência na indústria cerâmica de revestimento de Santa Catarina. Ensaios FEE, Porto Alegre, v. 21, n. 1, p. 144-61, 2000.

CHAIN, C. P. Abordagem geoestatística para identificação de potenciais clusters industriais. 2018. 99 f. Tese (Doutorado em Administração) - Universidade Federal de Lavras, Lavras, MG, 2018.

CONNELL, J.; VOOLA, R. Knowledge integration and competitiveness: a longitudinal study of an industry cluster. Journal of Knowledge Management, Sydney, v. 17, n. 2, p. 208-25, 2013.

CROCCO, M.; GALINARI, R.; SANTOS, F.; LEMOS, M. B.; SIMÕES, R. Metodologia de identificação de aglomerações produtivas locais. Nova Economia, Belo Horizonte, v. 16, n. 2, p. 211-41, 2006.

CROCCO, M.; SANTOS, F.; SIMÕES, R.; HORÁCIO, F. Industrialização descentralizada- sistemas produtivos locais: o arranjo produtivo calçadista de Nova Serrana (MG). Parcerias Estratégicas, Brasília, v. 8, n. 17, p. 55-134, 2003.

FINGLETON, B.; IGLIORI, D.; MOORE, B. Custer dynamic: new evidence and projections for computing services in great britain. Journal of Regional Science, [s.I.], v. 45, n. 2, p. 283-311, 2005.

GEROLAMO, M. C.; CARPINETTI, L. C. R.; FLESCHUTZ, T.; SELIGER, G.. Clusters e redes de cooperação de pequenas e médias empresas: observatório europeu, caso alemão e contribuições ao caso brasileiro. Gestão \& Produção, São Carlos, v. 15, n. 2, p. 351-65, 2008.

GIULIANI, E. Cluster absorptive capacity: why do some clusters forge ahead and others lag behind? European Urban and Regional Studies, [s.I.], v. 12, n. 3, p. 269-88, 2005. 
GLAESER, E.; KALLAL, H. D.; SCHEINKMAN, J. A.; SHLEIFER, A. Growth in cities. The Journal of Political Economy, Chicago, v. 100, n. 6, p. 1126-52, 1992.

HILL, E. W.; BRENNAN, J. F. A methodology for identifying the drivers of industrial clusters: the foundation of regional competitive advantage. Economic Development Quarterly, Cleveland, v. 14, n. 1, p. 65-96, 2000.

IBGE. Comissão Nacional de Classificação. IBGE, Rio de Janeiro, [s.d.] Disponível em: https://cnae.ibge. gov.. r $/$ ?view=secao\&tipo=cnae\&versaosubclasse=10\&versaoclasse=7\&secao=C. Acesso em: 21 dez. 2019.

IGLIONI, D. C. Economia dos clusters industriais e desenvolvimento. São Paulo: FAPESP, 2001.

JAFFE, A. B.; TRAJTENBERG, M.; HENDERSON, R. Geographic localization of knowledge spillovers as evidenced by patent citations. The Quarterly Journal of Economics, Massachusetts, v. 108, n. 3, p. 57798, 1993.

JOÃO, S. L.; OLIVARES, G. L. Análise dos aglomerados produtivos nos municípios de Angra dos Reis, Campos e Petrópolis no estado do Rio de Janeiro. Revista Ibero-Americana de Estratégia, São Paulo, v. 13, n. 4, p. 122-35, 2014.

LARENTIS, F.; GIOVANELLA, R.; CISLAGHI, T. Sustentabilidade em clusters: proposição de um modelo conceitual. Revista Ibero-Americana de Estratégia, São Paulo, v. 12, n. 3, p. 212-41, 2013.

LINS, H. N. Florianópolis, cluster turístico? Revista Turismo em Análise, São Paulo, v. 11, n. 2, p. 55-70, 2000.

MARSHALL, A. Principles of economics. New York: Macmillan Publishers Limited, 2013.

MEYER-STAMER, J. Path dependence in regional development: persistence and change in three industrial cluster in Santa Catarina, Brazil. World Development, [s.I.], v. 26, n. 8, p. 1495-511, 1998.

MOSSIG, I.; SCHIEBER, L. Driving forces of cluster evolution - growth and lock-in of two german packaging machinery clusters. European Urban and Regional Studies, [s.I.], v. 23, n. 4, p. 594-611, 2016.

MYTELKA, L.; FARINELLI, F. Local clusters, innovation systems and sustained competitiveness. Rio de Janeiro: UNU/INTECH, 2000.

NETO, J. A. Redes de cooperação produtiva e clusters regionais. São Paulo: Atlas, 2000.

OLIVARES, G. P.; DACOL, P. R. T. Avaliação da contribuição de aglomerados produtivos para o desenvolvimento local no estado do Rio de Janeiro. Production, São Paulo, v. 24, n. 4, p. 833-46, 2014.

ORGANIZAÇÃO PARA A COOPERAÇÃO E DESENVOLVIMENTO ECONÔMICO [OCDE]. Boosting innovation: the cluster approach. 1. ed. Paris: OCDE Publishing, 1999.

OSINSKI, M.; PEREIRA, M. F; ROMAN, D. J; NETO MORAIS, S. Competitividade e clusters catarinenses. Reuna, Belo Horizonte, v. 19, n. 3, p. 65-88, 2014.

PIEKARSKI, A. E. T.; TORKOMIAN, A. L. V. Identificação de clusters industriais: uma análise de métodos quantitativos. Gerpros, Bauru, v. 1, n. 1, p. 40-50, 2005.

PORTER, M. E. Cluster and competition. In: PORTER, M. E. (Ed.). On competition. 11. ed. Boston: Harvard Business School Publisching, 2008. p. 308-412.

PORTER, M. E. Clusters and the new economics of competition. Massachusetts: Harvard Business Review, 1998, p. 77-90. 
PORTER, M. E. The competitive advantage of nations. New York: Free Press, 1990.

REZENDE, A. C.; CAMPOLINA, B.; PAIXÃO, A. N. DA. Clusterização e localização da indústria de transformação no Brasil entre 1994 e 2009. Revista Econômica do Nordeste, Fortaleza, v. 43, n. 4, p. 27-50, 2012.

RISSETE, C. R.; MACEDO, M. M.; MEINERS, W. E. M. A. Identificação e tipologia de clusters da região metropolitana de Curitiba. In: ENCONTRO DE ECONOMIA PARANAENSE, 2., 02/out. a 04/out., Maringá. Anais [...]. Maringá: UEM/UEL/UEPG/UNIOESTE/IPARDES, 2003.

ROELANDT, T. J. A.; HETOG, P. Cluster analysis and cluster-based policy making in OECD countries: an introduction to the theme. In: OCDE. Boosting innovation: the cluster approach. 1. ed. Paris: OCDE Publishing, 1999. p. 9-23.

ROSA, H. R. Indústria e desenvolvimento regional: o caso do polo industrial de calçados de São João Batista/SC. Revista Geografia e Pesquisa, São Paulo, v. 9, n. 1, p. 51-60, 2015.

SCHMITZ, H. Collective efficiency and increasing returns. Cambridge Journal of Economics, Cambridge, v. 23, n. 4, p. 465-83, 1999.

SCUR, G.; GARCIA, R. The impact of actors, networks and institutions in the cluster's evolution: the case of the Brazilian ceramic tile industry. Competitiveness Review, [s.I.] v. 29, n. 3, p. 267-86, 2019.

SUZIGAN, W.; FURTADO, J.; GARCIA, R.; SAMPAIO, S. Clusters ou sistemas locais de produção: mapeamento, tipologia e sugestões de políticas. Revista de Economia Política, São Paulo, v. 24, n. 4, p. 543-62, 2004.

TADDEO, R.; SIMBOLI, A.; IOPPOLO, G.; MORGANTE, A. Industrial symbiosis, networking and innovation: the potential role of innovation poles. Sustainability, Basel, v. 9, n. 2, p. 169-186, 2017.

UNITED NATIONS CONFERENCE ON TRADE AND DEVELOPMENT [UNCTAD]. Promoting and sustaining SMEs clusters and networks for development. Geneva: United Nations, 1998.

VERSCHOORE, J. R.; BALESTRIN, A. Fatores relevantes para o estabelecimento de redes de cooperação entre empresas do Rio Grande do Sul. Revista de Administração Contemporânea, Maringá, v. 12, n. 4, p. 1043-69, 2008.

VIANNA, S. L. G.; HOFFMANN, V. E. Classificaçõo dos municípios catarinenses com base nos indicadores para a formação de um cluster de turismo cultural. Caderno Virtual de Turismo, Rio de Janeiro, v. 9, n. 2, p. 1-16, 2009.

WALUSZEWSKI, A. A competing or co-operating cluster or seven decades of combinatory resources? What's behind a prospering biotech valley? Scandinavian Journal of Management, [s.l.], v. 20, n. 1-2, p. 125-50, 2004.

YUSUF, Y. Y.; MUSA, A.; DAUDA, M.; EL-BERISHY, N.; KOVVURI, D.; ABUBAKAR, T. A study of the diffusion of agility and cluster competitiveness in the oil and gas supply chains. International Journal of Production Economics, München, v. 147, n. 1, p. 498-513, 2014.

\section{Sobre os autores:}

Sérgio Begnini: Doutorado em Administração pela Universidade do Oeste de Santa Catarina (UNOESC). Mestrado em Gestão e Desenvolvimento Regional pela Universidade Estadual do Oeste do Paraná (UNIOESTE). Especialização em Educação Integral pela Universidade Federal da Fronteira Sul (UFFS). Bacharelado em Administração pela Faculdade Concórdia (FACC) 
Atualmente, exerce o cargo de administrador na UFFS e é professor na UNOESC. É membro do grupo de pesquisa Competitividade Organizacional na UNOESC.E-mail: sergiobegnini@gmail.com, Orcid: https://orcid.org/0000-0002-7030-6107

Carlos Eduardo Carvalho: Doutorado em Administração e Turismo pela Universidade do Vale do Itajaí (UNIVALI). Mestrado em Administração pela Fundação Universidade Regional de Blumenau (FURB). Especialização em Processamento de Dados pela Universidade do Contestado (UNC). Graduação em Administração pela UNC. Atualmente é vice-reitor na Universidade do Oeste de Santa Catarina (UNOESC) em Chapecó. Atua como docente no doutorado acadêmico em Administração e no mestrado profissional em Administraçãona UNOESC.E-mail: carlos.carvalho@unoesc.edu.br, Orcid: https://orcid.org/0000-0002-7157-0743 